\title{
A century of Hawley retainer
}

\author{
Dr. Samikshya Paudel'; Dr. Rabindra Man Shrestha2; Dr. Sristi Napit ${ }^{3}$ \\ 'Post- Graduate Resident, ${ }^{2}$ Professor \\ Department of Orthodontics, Kantipur Dental College- Kathmandu University, Kathmandu, Nepal \\ ${ }^{3}$ Dental Surgeon, Lotus Dental Clinic, Pokhara, Nepal \\ Corresponding author: Dr. Samikshya Paudel; Email: paudelkeshari@gmail.com
}

\section{ABSTRACT}

Introduction: The use of Hawley retainer has crossed a century with same basic principles incorporated one hundred years back accompanying little improvisation in material. The innovation of Hawley retainer was a simple orthodontic appliance yet innovative device of retention of that period of time. The primitive appliance is still continuing over a century; is an achievement in itself. This clearly reflects the intense invention of an inquisitive mind of its creator, Dr. Charles Augustus Hawley.

The present article reviews the chronological events of the life of Dr. Charles Augustus Hawley and his contributions to the profession. Special emphasis has been laid on the evolution, development and clinical aspects of Hawley retainer commemorating its completion of a century.

KEYWORDS: Hawley retainer, Orthodontic Appliance, Retention.

\section{INTRODUCTION}

\section{About Dr. Charles Augustus Hawley}

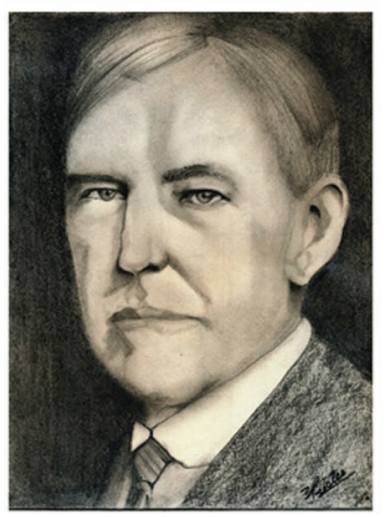

Figure 1: Dr. Charles Augustus Hawley (Redrawn from: Wahl N. Orthodontics in 3 millennia) ${ }^{1}$

Dr. Charles Augustus Hawley (Figure 1), was born in Avery, Ohio, USA on March 13, 1861 as a son of Noah $\mathrm{M}$ and Abigail (Mowry) Hawley. ${ }^{1,2} \mathrm{He}$ attended public schools of Columbus, Ohio and the Ohio State University, and graduated from the University of Michigan Dental School in 1893. ${ }^{2}$ After that, he worked at Ann Arbor in the Department of Operative Dentistry, wherein he became the first person to use nitrous oxide as an anesthetic agent for the removal of teeth. ${ }^{3}$ Later, he joined Edward H. Angle School of Orthodontia and graduated in 1905. ${ }^{3}$

After graduation, Hawley moved to Washington DC in 1908 and worked there as the first certified orthodontist. ${ }^{4}$ Also, he upgraded his studies on anatomy and physiology of dentition at the National History Museum at Washington. ${ }^{5}$

Coupled with great mechanical dexterity and practical mind, Hawley invented new instruments and methods for carrying out his treatment strategies. According to Hoffman, he was one of the first few orthodontists who recognized an association between unpleasing facial profile and protrusive dentition. ${ }^{3} \mathrm{He}$ has given invaluable contributions to the profession of dentistry and orthodontic specialty; such as: gold annealer, different orthodontic instruments, geometrical charts for predetermining the dental arch and Hawley retainer. ${ }^{1,6}$

Besides, Hawley had published outstanding literature in the field of dentistry and orthodontic specialty in his lifetime, ${ }^{2}$ which are enlisted below in Table 1. 
Table 1: Topics of literature published by Dr. Charles Augustus Hawley

\begin{tabular}{|l|l|}
\hline Year & Literature topics \\
\hline 1903 & The cohesion of gold \\
\hline 1904 & Relief from pain in Orthodontia \\
\hline 1904 & $\begin{array}{l}\text { The determination of the normal arch and } \\
\text { its application to Orthodontia }\end{array}$ \\
\hline 1906 & An accurate method in Orthodontia \\
\hline 1910 & $\begin{array}{l}\text { The function of the teeth in the development } \\
\text { of the face }\end{array}$ \\
\hline 1919 & A removable retainer \\
\hline 1920 & The problem of retention \\
\hline 1921 & The postoperative treatment of Class II \\
\hline 1923 & The principles and art of retention \\
\hline 1924 & $\begin{array}{l}\text { The use of the round wire in bracket bands } \\
\text { preliminary to adjusting the ribbon arch }\end{array}$ \\
\hline 1925 & Orthodontic Photography \\
\hline 1925 & The value of gnathostatic models \\
\hline 1929 & Treatment of Class II or disto-occlusion \\
\hline
\end{tabular}

(Source: FTM. In memorium: Hawley CA. Int J Orthod Dent Children. 1929) ${ }^{2}$

Hawley was actively involved in various scholarly groups of the specialty. In 1908, he became President of the American Society of Orthodontists (presently, American Association of Orthodontists). He also served as the President of District of Columbia Dental Society (1920) and a Fellow of the American College of Dentists. Later, he was President of the New York Society of Orthodontists (1929) and President-elect of the Southern Society of Orthodontists (1929). ${ }^{3}$

At the age of sixty-eight on 22nd July 1929, he died at Garfield Hospital, Washington DC, following the complications of an operation, leaving behind his wife Evelyn Frank Hawley, a step-son Archibald Donovan Hawley and a daughter Carlotta Augusta Hawley.1-3 His daughter followed his footsteps after his death, became an ABO-certified orthodontist and worked as the first woman secretary of Washington-Baltimore Society of Orthodontics. $1,7,8$

From his memoirs, one can find that he was a farsighted orthodontist and a simple man who loved duck hunting, playing golf and photography. ${ }^{2}$ He has left us with a simple innovative option for retention, the Hawley retainer, that is serving us beyond a century with the same principle and efficiency.

\section{The "Hawley Removable Retainer"}

In 1906, Hawley visited the office of Dr. R.D. McBride where he encountered a retaining device (Figure 2), that was useful to retain the corrected position of rotated teeth. It was efficient, but it had some repulsive features that needed alterations. The flat pieces between first molar and second premolar were a site for food lodgments demanding the removal of retainer for few days. ${ }^{6}$ The labial bar was too heavy without supports and the bite planes for holding it mesiodistally were interfering the stability of appliance. ${ }^{9}$

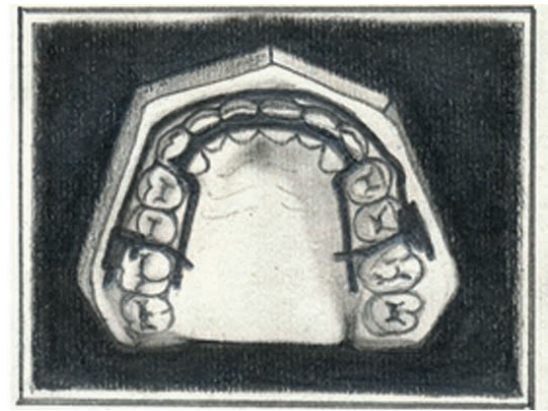

Figure 2: Removable retainer made by Dr. R.D. McBride (Redrawn from: Hawley CA. A removable retainer). ${ }^{6}$

Inspired from the retaining device, Hawley developed a new appliance and started using it. He discussed about the retainer in the meeting of the American Society of Orthodontists on July 1918 at Chicago. After one year, on 1 st June 1919, he introduced this appliance (Figure 3 and 4), in his paper as "A removable retainer", which was made from four components, namely; a flat labial wire from cuspid to cuspid of $0.022 \times 0.036$, 19-gauge gold wire formed into loops, a bicuspid clasp extending backward from the wire, all of which get support from palatal/lingual plate made from vulcanite. ${ }^{1}$ In lower arch, a wire spur extends into occlusal surface between lingual cusps to prevent the plate from downward displacement during mastication.
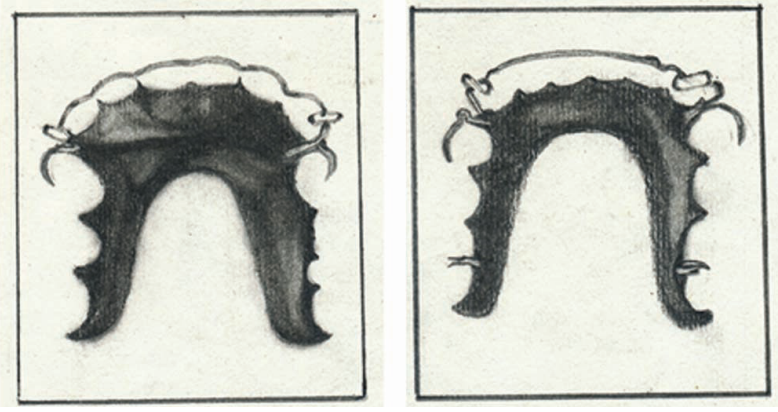

Figure 3: Removable Hawley retainer. A. In upper arch, B. In lower arch (Redrawn from: Hawley CA. A removable retainer). ${ }^{6}$

In 1922-1923, Hawley presented a paper titled "The 
principle and art of retention" in European Orthodontic Society (as cited in the Transactions of the European Orthodontic Society), wherein he perceived mixed comments about Hawley retainer. ${ }^{9}$ He also introduced a modified bicuspid clasp (Figure 5), with a spring or elastic adjustment loop above the attachment to the main wire such that it can be raised or lowered. An important remark was from W.S. Davenport, who mentioned that Hawley retainer was a simple device made from the combination of old features of clasp and plate with equal consideration on fundamental principles of retention. Further, he stated that it excluded the shortcomings of retaining device made by Dr. Mcbride and Kingsley Appliance. ${ }^{9}$

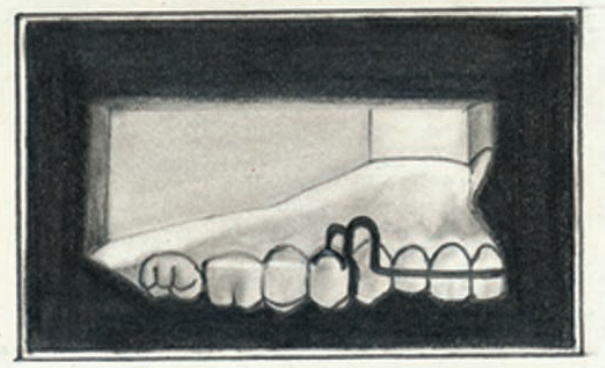

Figure 4: Removable Hawley retainer with modified bicuspid clasp (Redrawn from: Hawley CA. The principle and art of retention). ${ }^{9}$

With time, Hawley retainer gained popularity among orthodontists and had undergone series of modifications in its components. Ernest Bach (1927), ${ }^{10}$ Holt (1928), ${ }^{11}$ Hutchinson (1931), ${ }^{12}$ Reid (1935), ${ }^{13}$ Anderson (1936), ${ }^{14}$ Mclntosh (1940), ${ }^{15}$ Sved (1944) ${ }^{16}$ presented modified versions of Hawley retainer to improve clinical failures. After the development of acrylic resins in dentistry, Stevenson improvised Hawley retainer (1941), using acrylic instead of vulcanite, thus making the fabrication simpler and more economic. ${ }^{17}$ With the introduction of modified arrowhead clasp (Figure 6 and 7) and its modifications by Phillip Adams (1953); the Adams clasp gained popularity in removable appliances. ${ }^{18}$ It ensured retention in clinical situations, which otherwise was difficult with removable appliances. ${ }^{19}$ Since then, Adams clasp has been incorporated in Hawley retainer.

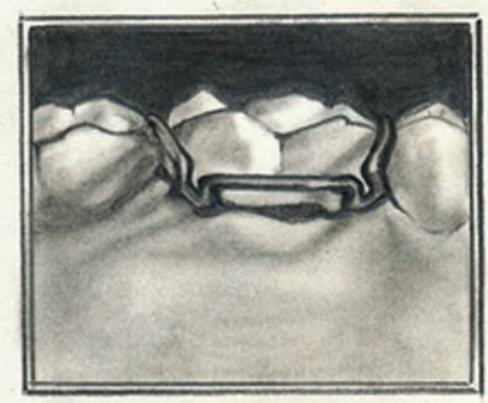

Figure $5 \mathrm{~A}$

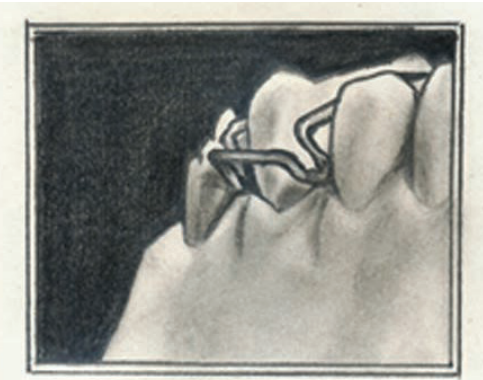

Figure 5 B

Figure 5: Modified arrowhead clasp. A: Front view, B: Lateral view (Redrawn from: Adams CP. The retention of removable appliances with the modified arrowhead clasp). ${ }^{18}$

\section{Ideal requirements of Hawley retainer}

1. Hawley retainer should maintain the corrected functional occlusion, $^{20}$ periodontal health ${ }^{21-24}$ and muscular balance, ${ }^{19}$ achieved by the orthodontic treatment.

2. It should hold the expansion and form of the arch. ${ }^{6}$

3. The appliance should prevent the rotation of teeth after treatment. ${ }^{6}$

4. The overbite must be established. ${ }^{6}$

5. The retainer should be biocompatible, economical and easy to clean with its components resistant to tarnish and corrosion.

\section{Fabrication}

Hawley retainer is fabricated with acrylic resin that covers the palate, a stainless-steel bow contouring the labial aspect of maxillary anterior teeth, with $U$ loops extending from distal surface of canines, and palatally embedding in the acrylic resin. ${ }^{25}$ Besides, it incorporates clasps like Adams clasp, circumferential clasp or ballend clasp, for retention.

The acrylic plate is processed with heat-cure or chemical cure resin. The thickness of plate is made of adequate bulk of $2-3 \mathrm{~mm}$ to retain the wire components, with maximal attention to the patient comfort and adaptation into embrasures. ${ }^{26}$ Its distal margin terminates distal to first molars, and is thinned to merge with the palatal mucosa.

The wire component includes stainless steel wire of 0.7 $\mathrm{mm}$ for Adams clasp, $0.9 \mathrm{~mm}$ for circumferential clasp or ball end clasp and $0.7 \mathrm{~mm}$ for labial bow. ${ }^{27}$ The $U$ loop is fabricated 2-3 $\mathrm{mm}$ above the gingival margin of canine and free from gingival contact to avoid injury or pressure effect in gingiva. The labial bow is kept passive and in gentle contacts with labial surface of the teeth. ${ }^{26}$

\section{Modifications}

Hawley retainer can be modified according to the clinical requirement for retention.6,28 The selection of clasp design is important as clasp crossing the occlusal table can disrupt the corrected tooth relationships.23 Some modifications are listed in Table 2. 
Table 2: Modifications of Hawley retainers

\begin{tabular}{|l|l|}
\hline Modification & Uses \\
\hline Hawley with anterior bite plane & $\begin{array}{l}\text { Anterior bite plane can be fabricated in its palatal portion to control bite depth, } \\
\text { in corrected deep bite cases.6 }\end{array}$ \\
\hline $\begin{array}{l}\text { Hawley with bow soldered to } \\
\text { buccal section of Adams clasp }\end{array}$ & $\begin{array}{l}\text { In tight contacts, there can be wedging effect due to cross-over wire. To } \\
\text { overcome this, labial bow can be soldered to the bridge of Adams clasp which } \\
\text { helps to maintain the closed extraction site.28 }\end{array}$ \\
\hline Hawley with long labial bow & $\begin{array}{l}\text { The drawback of space opening between canine and premolar, with standard } \\
\text { Hawley retainer can be prevented with the use of labial bow extending from } \\
\text { first premolar of one side to another side.28 }\end{array}$ \\
\hline $\begin{array}{l}\text { Hawley with C-clasp on second } \\
\text { molars distally }\end{array}$ & $\begin{array}{l}\text { When there is chance of occlusal interference over posterior occlusion, c-clasp } \\
\text { with distally approaching ring on second molars, can be fabricated.23 }\end{array}$ \\
\hline Hawley with fitted labial bow & $\begin{array}{l}\text { Fitted labial bow anteriorly and the base plate posteriorly is used for better } \\
\text { incisors control. }\end{array}$ \\
\hline Hawley with finger/Z-spring & $\begin{array}{l}\text { The incorporation of finger/ Z-springs makes it active appliance used to } \\
\text { achieve tipping movement. }\end{array}$ \\
\hline
\end{tabular}

\section{Recent Advances}

Hawley with clear outer bow: The aesthetic variant of Hawley retainer was presented by Needham et al in 2015. The appliance was made aesthetic with the incorporation of clear outer bow made of food-grade polyethylene terephthalate of $2.75 \mathrm{~mm}$ width, joined at a Coiltight-Joint ${ }^{\circledR}$ to the Adams clasp. It adapts more accurately to the contour of all anterior teeth while posteriorly the wire segment provides retentive component. ${ }^{29}$

\section{Advantages of Hawley Retainer}

1. The armamentarium required for fabrication of Hawley retainer are easily available and sophisticated laboratory set up are not necessary.

2. Being a removable retainer, it can be removed for cleaning, brushing and sometimes, in social occasions.

3. It allows posterior settling and improvement in occlusal contacts. ${ }^{30}$

4. It can be adjusted according to clinical condition for finished treatments.

5. It is a durable retainer and easily repairable if the components are broken.

6. For a larger period of time, patient compliance is better with Hawley retainer. ${ }^{31}$

\section{Disadvantages}

1. Success of the treatment depends upon patient's compliance.

2. The display of labial wire is unaesthetic, which affects the patient's satisfaction.
3. There is a higher evidence of breakage of this retainer than its loss. ${ }^{32}$

4. It may not hold the corrected labial segments in upper and lower arch for a larger period of time due to insufficient contact surfaces leading to relapse and incisor crowding. . $^{33,34}$

5. In the first few weeks, patients experience problem in speech articulations. ${ }^{32,35-37}$

\section{Duration of wear and retention protocol}

For the first 2-6 months, Hawley had advised the continuous use of the retainer with removal only during cleaning. After six months, night time wear is recommended for about a year followed by several days or week of left out periods and again usage at nights to ensure that teeth are not changing their positions. ${ }^{6}$

However, a comprehensive research conducted at the University of Washington, highlighted that retention for life is the only way to ensure satisfactory alignment of the teeth as orthodontic treatment were mostly unstable over a long time. ${ }^{23}$

Many studies have been performed by different authors regarding the duration of wear, ${ }^{23,38}$ material biocompatibility, monitoring of its wear by the orthodontist, ${ }^{40}$ hygiene, ${ }^{41,42}$ durability, ${ }^{32,43}$ function, ${ }^{30,34-36,44}$ and patient satisfaction. ${ }^{31}$ Also, there are comparison studies between Hawley retainers (HRs) and vacuum formed retainers (VFRs) or positioners highlighting its merits and demerits. ${ }^{30-36,39,41-44}$ Some of the studies are tabulated in Table 3 
Table 3: Studies related to Hawley retainers

\begin{tabular}{|c|c|}
\hline Author & Inference \\
\hline Sauget $(1997)^{30}$ & $\begin{array}{l}\text { During first three months of retention, Hawley retainer allowed relative settling of } \\
\text { posterior teeth while clear overlay retainers maintained the corrected tooth position. }\end{array}$ \\
\hline Zhang \& Wang (2003) $)^{41}$ & $\begin{array}{l}\text { Positioner had more periodontal index grading than HRs necessitating proper oral } \\
\text { health care to preserve periodontal tissues. }\end{array}$ \\
\hline Hichens $(2007)^{32}$ & $\begin{array}{l}\text { HRs had more breakages, was costlier and associated with less patient satisfaction } \\
\text { than VFRs. }\end{array}$ \\
\hline Rowland $(2007)^{33}$ & $\begin{array}{l}\text { HRs were found to have clinically less significant retention of the mandibular labial } \\
\text { segment than VFRs. }\end{array}$ \\
\hline Rinchuse $(2007)^{23}$ & $\begin{array}{l}\text { Life-time of retainer wear, whether removable or fixed, was a suitable option for } \\
\text { orthodontic treatment stability. }\end{array}$ \\
\hline Valiathan \& Hughes $(2010)^{47}$ & $\begin{array}{l}\text { In maxilla Hawley retainers; and in mandible fixed lingual retainers are most } \\
\text { commonly used. }\end{array}$ \\
\hline Shawesh $(2010)^{38}$ & $\begin{array}{l}\text { Full or part-time wear regimen of HRs, both was equally effective during one-year } \\
\text { period. Clinically, only night time wear for one year can be recommended to the } \\
\text { patients. }\end{array}$ \\
\hline Barlin $(2011)^{34}$ & $\begin{array}{l}\text { Relapse is not affected by the choice of retainer as it occurred in both groups of HRs } \\
\text { and VFRs group }\end{array}$ \\
\hline Sun $(2011)^{43}$ & $\begin{array}{l}\text { Hawley retainer and VFRs both had undergone fractures but the site of fracture was } \\
\text { different. The clinician should avoid increase in buccal root torque and reinforce the } \\
\text { retainer base plates to prevent it. }\end{array}$ \\
\hline Pratt $(2011)^{31}$ & $\begin{array}{l}\text { For periods longer than two years after debonding, patient compliance was greater } \\
\text { with Hawley retainers. }\end{array}$ \\
\hline Demir $(2012)^{44}$ & $\begin{array}{l}\text { Over two-year period, retention characteristics of VFRs and HRs were similar as } \\
\text { irregularity index increased in both groups. }\end{array}$ \\
\hline Hyun $(2015)^{40}$ & $\begin{array}{l}\text { The compliance of patient increased clinically, when patient was aware of being } \\
\text { monitored over the use of Hawley retainer. }\end{array}$ \\
\hline Raghavan $(2017)^{39}$ & $\begin{array}{l}\text { Hawley retainer fabricated by heat-cure acrylic resin was a favorable choice over } \\
\text { cold-cure acrylic and VFRs in terms of bis-phenol A release. }\end{array}$ \\
\hline Wan $(2017)^{35}$ & Changes in articulation were more obvious in the HR group than VFRs group. \\
\hline Atik $(2017)^{36}$ & $\begin{array}{l}\text { Articulation in consonant-vowel combination were affected by Hawley retainers } \\
\text { more than Essix retainers. }\end{array}$ \\
\hline Manzon $(2018)^{42}$ & $\begin{array}{l}\text { Oral hygiene and retainer hygiene were better with Hawley retainers while Essix } \\
\text { retainers were more comfortable and esthetic. }\end{array}$ \\
\hline
\end{tabular}

\section{DISCUSSION}

The retention of corrected occlusion is the most important step after orthodontic treatment. As such, incorporation of basic principles in a retaining device to avoid rotation, tipping, and maintenance of bite depth, is a must. The innovation of Hawley retainer by Dr. Charles Hawley, has been an impeccable addition in this retention phase.

Hawley retainers (HRs) have crossed hundred years of its fabrication and still, these are the most used removable appliance for maxillary retention. ${ }^{23,24}$ These are available in majority of clinic with least laboratory instruments and costs. Having a lot of modifications, it covers a range of clinical conditions from occlusal settling to anterior deep bite correction. A traditional Hawley retainer allows settling and thus an improvement in posterior occlusal contacts. ${ }^{30}$

In our clinical context, Hawley retainer is an appropriate 
choice when durability is a question. Some authors have inferred that Hawley retainers lasts longer than 15 years. ${ }^{23}$ However, a study by Hichens et al. found that there are greater breakages in HRs group than its loss. ${ }^{32}$

For most patients, first few weeks of use of this retainer is a demanding process with difficulties in speech articulations and chewing. ${ }^{32,35,36}$ According to a systematic review by Chen $\mathrm{J}$ et al., HRs had often caused speech distortion of /s/, /z/, /t/, /d/, /i/, /3/, / / /, and / $/ /$ sounds, and the impairment could last up to 3 months. ${ }^{37}$

There is an esthetic concern for the appliance, due to metallic display of wire, creating an unpleasing experience among patients. Hawley retainer with clear outer bow (aesthetic Clearbow ${ }^{\circledR}$ ) can be used in such circumstances. ${ }^{28,29}$ It also provides benefits of being free from bisphenol-A.

Bisphenol-A (BPA) is a synthetic compound enlisted by WHO (2011), as an endocrine disruptive chemical. ${ }^{39} \mathrm{~A}$ study by Raghavan et al concluded that Vacuum formed retainers (VFRs) showed greatest release of BPA followed by chemically cured HRs and least with HRs processed by heat cure. ${ }^{39}$ Thus, Hawley retainer (either with Clearbow ${ }^{\circledR}$ or heat-cured resin), is a biocompatible option among the retainers.

Being a removable appliance, it can be cleaned thoroughly by the patient. Comparison of these retainers with thermoplastic resins concluded that HRs were more hygienic with less accumulation of plaque in the teeth or retainer. ${ }^{41}$

When retainer is prescribed for a short period of six months, VFRs have been found to be cost-effective with better compliance but for a duration of more than two years, Hawley retainers were more effective. ${ }^{31}$ Similarly, in developing countries, HRs are considered a cheaper alternative over clear thermoplastic retainers. However, systematic reviews on comparison of these retainers could not draw a high level of evidence to support the benefits of one above the other in terms of costeffectiveness and patient satisfaction. ${ }^{26,45,46}$

Relapse was evident over two years in the anterior region of mandibular teeth in majority of retainers. ${ }^{44}$ Though irregularity index decreased in VFRs groups, it could not be concluded that HRs are less effective than VFRs in terms of irregularity of incisors and intercanine and intermolar widths. ${ }^{44}$
In terms of appliance wear, a survey-based study in US reported that eighty-one per cent of orthodontists prescribed a full-time wear period between 3-9 months for Hawley retainers compared with clear thermoplastic retainers (less than 3 months). ${ }^{47}$ Reitan's concept of rearrangement of gingival and periodontal fibers after 8 months might explain the rationale behind the full-time wear for 3-9 months. ${ }^{48}$ However, there is unavailability of sufficient evidence to favor a particular regimen. ${ }^{49}$ In majority of clinical scenarios, patients are reviewed for over two years after the end of active orthodontic treatment..$^{50}$ Thus, the retention protocol is largely determined by orthodontist's experience, patient's expectations, and clinical circumstances.

There are certain limitations to this study. It is not a systematic research and do not follow a certain protocol. Thus, it lacks the profundity of comprehensive knowledge beyond the topic of interest and may be subjected to bias during selection of literature. However, it provides an overview about the appliance, its associated history and its use through the century.

\section{Conflict of Interest}

None.

\section{Acknowledgement}

The figures were charcoal sketches redrawn by coauthor Dr. Sristi Napit. 


\section{REFERENCES}

1. Wahl N. Orthodontics in 3 millennia. Chapter 5: the American Board of Orthodontics, Albert Ketcham, and early 20th-century appliances. Am J Orthod Dentofac Orthop. 2005 Oct;128(4):535-40.

2. FTM. In memorium: Charles Augustus Hawley. Int J Orthod Dent Children. 1929 Dec;15(12):1248-49.

3. Hoffman P. Charles A. Hawley. Am J Orthod. 1963 Feb;49(2):135-6.

4. Waugh LM. Guidance for tomorrow's practice gained from the pioneers of the Northeastern district. Am J Orthod. 1958 Aug;44(8):612-27.

5. Burke C. A century of influence: Part 1. Orthodontic pioneers. Am J Orthod Dentofac Orthop. 2015 May; 147(5):155-60.

6. Hawley CA. A removable retainer. Int J Orthod Oral Surg (1919). 1919 Jun ;5(6):291-305.

7. Burke C, Troehler L, Behrents RG. 100 years of publishing, 100 people of influence. Am J Orthod Dentofac Orthop. 2015;147(Suppl-2):147-8.

8. Wahl N. Orthodontics with a tender touch. Angle Orthod. 1992 Dec;62(4):307-13.

9. Hawley CA. The principles and art of retention. Transactions of the European Orthodontic Society. 1922/1923;5-14 [In Euro J Orthod. 2007 Apr;29(Suppl-1):16-22].

10. Bach EN. Cast Hawley retainer with attachments showing advantages over the vulcanite retainer. Am J Orthod Dentofac Orthod. 1927 Nov; 13(11):987-8.

11. Holt AB. Removable anterior section for Hawley retainers. Am J Orthod Dentofac Orthop. 1928 Jun;14(6):524-5.

12. Hutchinson D. The Hawley removable retainer. Am J Orthod Dentofac Orthop. 1931 Sep;17(9):885-6.

13. Reid PV. A new labial section for the Hawley retainer. Am J Orthod Dentofac Orthop. 1935 Feb;21(2):201-2.

14. Anderson GM. Mandibular retainers with incisor springs and an appliance designed to assist in breaking tongue habits. Int J Orthod Oral Surg. 1936 Aug;22(8):813-4.

15. McIntosh FE. Retention procedures. Am J Orthod Oral Surg. 1940 Jan;26(1):37-40.

16. Sved A. Changing the occlusal level and a new method of retention. Am J Orthod Oral Surg. 1944 Oct;30(10):527-35.

17. Stevenson WB. An easy and inexpensive method of making Hawley retainers. Am J Orthod Dentofac Orthop. 1941 Mar;27(3):154-5.

18. Adams CP. The retention of removable appliances with the modified arrowhead clasp. Euro J Orthod. 2007 Apr;29(suppl-1):68.

19. Adams CP. Removable appliances yesterday and today. Am J Orthod Dentofac Orthop. 1969 Jun;55(6):748-64.

20. Kuramae M, Almeida MH, Noüer DF, Magnani MB. Main factors related to orthodontic stability. a literature review. J Bras Orthod Orthop Facial. 2002 May;(39): 194-200.

21. Bicalho JS, Bicalho KT. Descriçäo do método de contençäo fixa, com livre acesso do fio dental. Rev Dent Press Orthod Orthop Maxilar. 2001:97-104.

22. Booth FA, Edelman JM, Proffit WR. Twenty-year follow-up of patients with permanently bonded mandibular canine-to-canine retainers. Am J Orthod Dentofac Orthop. 2008 Jan 1;133(1):70-6.

23. Rinchuse DJ, Miles PG, Sheridan JJ. Orthodontic retention and stability. a clinical perspective. J Clin Orthod. 2007 Mar;41(3):125.

24. Silveira M. O uso do PET (Polietileno Tereftalato) na construçäo de contençöes ortodônticas removíveis. J Bras Orthod Orthop Facial. 1998:33-7.

25. Assumpção WK, Ota GK, Ferreira RI, Cotrim-Ferreira FA. Orthodontic retainers: analysis of prescriptions sent to laboratories. Dent Press $J$ Orthod. 2012 Apr;17(2):36-e1.

26. Kharbanda OP. Orthodontics: Diagnosis of \& Management of Malocclusion \& Dentofacial Deformities. Elsevier Health Sciences; 2019 Dec 4.

27. Al Rahma WJ, Kaklamanos EG, Athanasiou AE. Performance of Hawley-type retainers: a systematic review of randomized clinical trials. Euro J Orthod. 2018 Apr;40(2):115-25.

28. Proffit WR, Fields HW, Larson B, Sarver DM. Contemporary orthodontics. Elsevier Health Sciences; 2018 Aug 6.

29. Needham R, Waring DT, Smith J, Malik OH. The invisible Hawley retainer. J Orthod. 2015 Dec;42(4):333-41.

30. Sauget E, Covell DA, Boero RP, Lieber WS. Comparison of occlusal contacts with use of Hawley and clear overlay retainers. Angle Orthod. 1997 Jun;67(3):223-30.

31. Pratt MC, Kluemper GT, Lindstrom AF. Patient compliance with orthodontic retainers in the postretention phase. Am J Orthod Dentofac Orthop. 2011 Aug;140(2):196-201.

32. Hichens L, Rowland H, Williams A, Hollinghurst S, Ewings P, Clark S, Ireland A, Sandy J. Cost-effectiveness and patient satisfaction: Hawley and vacuum-formed retainers. Euro J Orthod. 2007 Aug;29(4):372-8.

33. Rowland H, Hichens L, Williams A, Hills D, Killingback N, Ewings P, Clark S, Ireland AJ, Sandy JR. The effectiveness of Hawley and vacuumformed retainers: a single-center randomized controlled trial. Am J Orthod Dentofac Orthop. 2007 Dec;132(6):730-7.

34. Barlin S, Smith R, Reed R, Sandy J, Ireland AJ. A retrospective randomized double-blind comparison study of the effectiveness of Hawley vs vacuum-formed retainers. Angle Orthod. 2011 May;81(3):404-9.

35. Wan J, Wang T, Pei X, Wan Q, Feng W, Chen J. Speech effects of Hawley and vacuum-formed retainers by acoustic analysis: A single-center randomized controlled trial. Angle Orthod. 2017 Mar;87(2):286-92. 
36. Atik E, Esen Aydınlı F, Kulak Kayıkçı ME, Ciğer S. Comparing the effects of Essix and Hawley retainers on the acoustics of speech. Euro J Orthod. 2017 Aug;39(4):440-5.

37. Chen J, Wan J, You L. Speech and orthodontic appliances: a systematic literature review. Euro J Orthod. 2018 Jan;40(1):29-36.

38. Shawesh M, Bhatti B, Usmani T, Mandall N. Hawley retainers full-or part-time? A randomized clinical trial. Euro J Orthod. 2010 Apr;32(2):165-70.

39. Raghavan AS, Sathyanarayana HP, Kailasam V, Padmanabhan S. Comparative evaluation of salivary bisphenol A levels in patients wearing vacuum-formed and Hawley retainers: An in-vivo study. Am J Orthod Dentofac Orthop. 2017 Mar;151(3):471-6.

40. Hyun P, Preston CB, Al-Jewair TS, Park-Hyun E, Tabbaa S. Patient compliance with Hawley retainers fitted with the SMART® sensor. a prospective clinical pilot study. Angle Orthod. 2015 Mar;85(2):263-9.

41. Zhang B, Wang Q. Periodontal implication of positioner versus removable retainer. Beijing J Stomatol. 2003;3:146-7.

42. Manzon L, Fratto G, Rossi E, Buccheri A. Periodontal health and compliance: A comparison between Essix and Hawley retainers. Am J Orthod Dentofac Orthop. 2018 Jun; 153(6):852-60.

43. Sun J, Yu YC, Liu MY, Chen L, Li HW, Zhang L, Zhou Y, Ao D, Tao R, Lai WL. Survival time comparison between Hawley and clear overlay retainers: a randomized trial. J Dent Research. 2011 Oct;90(10):1197-201.

44. Demir A, Babacan H, Nalcacı R, Topcuoglu T. Comparison of retention characteristics of Essix and Hawley retainers. Korean J Orthod. 2012 Oct; 42(5):255-62.

45. Mai W, Meng H, Jiang Y, Huang C, Li M, Yuan K, Kang N. Comparison of vacuum-formed and Hawley retainers: a systematic review. Am J Orthod Dentofac Orthop. 2014 Jun;145(6):720-7.

46. Al-Moghrabi D, Pandis N, Fleming PS. The effects of fixed and removable orthodontic retainers: a systematic review. Prog Orthod. 2016 Dec;17(1):24.

47. Valiathan M, Hughes E. Results of a survey-based study to identify common retention practices in the United States. Am J Orthod Dentofac Orthop. 2010 Feb;137(2):170-7.

48. Littlewood SJ, Millett DT, et al. Retention procedures for stabilising tooth position after treatment with orthodontic braces. Cochrane Database Syst Rev. 2016 Jan;9(1):CD002283.

49. Reitan K. Tissue rearrangement during retention of orthodontically rotated teeth. Angle Orthod. 1959 Apr;29(2):105-13.

50. Wong PM, Freer TJ. A comprehensive survey of retention procedures in Australia and New Zealand. Aust Orthod J. 2004 Nov;20(2):99.

\section{List of figures}

Figure 1: Dr. Charles Augustus Hawley (Redrawn from: Wahl N. Orthodontics in 3 millennia. Chapter 5: the American Board of Orthodontics, Albert Ketcham, and early 20th-century appliances). ${ }^{1}$

Figure 2: Removable retainer made by Dr. R.D. McBride (Redrawn from: Hawley CA. A removable retainer) ${ }^{6}$

Figure 3: Removable Hawley retainer A. Upper arch, B. Lower arch (Redrawn from: Hawley CA. A removable retainer). ${ }^{6}$

Figure 4: Removable Hawley retainer with modified bicuspid clasp (Redrawn from: Hawley CA. The principle and art of retention). ${ }^{9}$

Figure 5: Modified arrowhead clasp; A. Front view, B. Lateral view (Redrawn from: Adams CP. The retention of removable appliances with the modified arrowhead clasp). ${ }^{18}$ 